\title{
Estabilidad laboral reforzada. La maternidad y la discapacidad ante el derecho
}

Reinforced labor stability motherhood and disability before the law

\author{
José Chávez-Fernández Postigo \\ Universidad Católica San Pablo, Arequipa, Perú
}

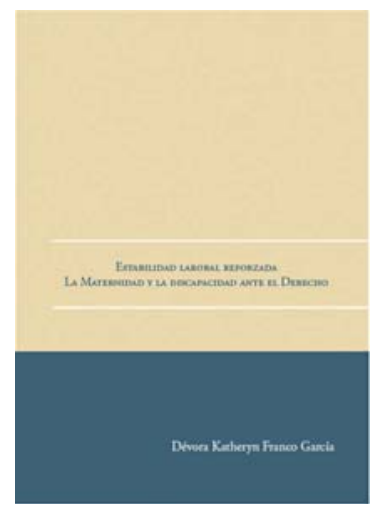

Franco García, Dévora Katheryn (2018).

Fondo Editorial de la Universidad Católica San Pablo Arequipa, Perú, pp. 89.

ISBN 978-612-4353-14-7

Estabilidad laboral reforzada. La maternidad y la discapacidad ante el derecho es el primer libro de la profesora de la Facultad de Derecho de la Universidad Católica San Pablo (UCSP) Dévora Franco García, y constituye el séptimo ejemplar publicado por esta facultad y el Fondo Editorial de la UCSP, en su colección Biblioteca Jurídica. Por ello, conviene, en primer lugar, dedicar al menos un párrafo a la presentación de la profesora Franco y, en segundo lugar, dar cuenta del objetivo y de la estructura básica de su trabajo, así como de lo que — a mi modo de ver- resultan ser los méritos más importantes de la obraํ․

Dévora Franco García es maestra en Derecho Constitucional por la Escuela de Postgrado de la Universidad Católica de Santa María — precisamente obtuvo dicho título en 2017 con la tesina que ha dado origen al libro y que se denominó "Análisis de

1 Debo dejar constancia de que la presente reseña reproduce casi en su totalidad el prólogo que redacté para el libro. 
la estabilidad laboral reforzada como garantía al derecho al trabajo y a no ser despedido por razón de maternidad o discapacidad"- - Es también abogada, graduada en 2004 con los máximos honores en la Facultad de Ciencias Jurídicas y Políticas de la misma casa de estudios; y tras una larga y fructífera experiencia profesional, es ahora profesora de Derecho Constitucional en la Facultad de Derecho de la UCSP, en la que trabaja a tiempo completo desde 2015.

Respecto de la obra, lo primero que es importante señalar es que si bien esta se aborda metodológicamente desde la perspectiva del derecho constitucional — que es la que cultiva con mayor dedicación Dévora Franco-, este trabajo tiene por objeto material el terreno jurídico fértil que se encuentra a caballo entre el derecho constitucional y el laboral. Es precisamente a través de dichas coordenadas epistemológicas que la autora se propone en este libro un objetivo de no sencilla consecución, pero que resulta del todo valioso, especialmente para los juristas que comparten con ella una perspectiva de hermenéutica constitucional axiológicamente comprometida con la eficacia real de los derechos sociales. La profesora Franco (2018) se aboca a demostrar que «[...] cuando una relación laboral involucra a una persona objeto de protección reforzada - se refiere precisamente a la madre en estado de gestación y a la persona con discapacidad-, el principio de "estabilidad laboral reforzada" debe tomar preeminencia para evitar que sean despedidos, salvo por causa justa» (pp. 17-18), por lo que - a su juicio-el amparo laboral terminaría siendo, en contraposición a lo sostenido explícitamente por el Tribunal Constitucional peruano (TC) en el precedente vinculante del caso Lara Garay, la vía procesal idónea para resolver el fondo del asunto en términos de eficacia restitutoria, incluso cuando el trabajador haya sido beneficiario de la indemnización por despido.

Para lograr este objetivo, la profesora Franco García divide su libro en tres capítulos. En el primero, con el propósito de sentar las bases teóricas del resto del estudio, se aborda el derecho al trabajo, y se le concibe dentro de la dinámica entre la libertad de trabajo y la libertad de contratar, que se materializa en el contrato de trabajo, poniendo particular énfasis en su conclusión como manifestación de la autonomía que tienen las partes para finalizar su relación contractual. En el segundo capítulo, la autora contrapesa, por un lado, la institución laboral de la "protección reforzada" desde el reconocimiento de la vulnerabilidad humana; y por otro lado, el despido, con el propósito de arribar al principio constitucional de la "estabilidad laboral reforzada" que es el que, a su modo de ver, debería primar cuando se trata del despido laboral que involucra a madres gestantes o a discapacitados. Finalmente, en el tercer capítulo, la profesora Franco afianza la demostración de su tesis a través del análisis de jurisprudencia relevante del TC, en particular, del conocido precedente vinculante que el máximo intérprete de la Constitución estableciera en el caso Lara Garay para proponer que ha de utilizarse la técnica del distinguishing para justificar 
jurisprudencialmente que dicho precedente no se aplica a los casos de estabilidad laboral reforzada que propone la autora.

Estamos frente a un trabajo que tiene muchos aspectos que merecerían ser destacados. Sin embargo, por cuestiones de espacio, me limitaré a poner de relieve solo dos de los que considero los más importantes. El primero es de carácter adjetivo o metodológico y el segundo, de carácter más bien sustantivo.

En primer lugar, nos encontramos frente a un libro muy bien escrito y que alcanza un equilibrio bastante logrado entre, por un lado, el trato exhaustivo de temas técnicos doctrinales y jurisprudenciales que requieren cierta complejidad en el abordaje y, por otro lado, una prosa clara y ágil, que hace a la obra bastante accesible para el público recién iniciado. El resultado es un trabajo que puede satisfacer tanto a los juristas profesionales y académicos interesados en temas de derecho laboral de relevancia y de hermenéutica constitucional como al público en general que empieza a adentrarse en dichas materias, que podrían parecerle a primera vista excesivamente complejas.

En segundo lugar, el tema abordado en el libro resulta de la mayor relevancia para un Estado constitucional de derecho como el peruano, en el que se necesita cada vez más que de manera original se aborden en sede de hermenéutica constitucional temas de derechos sociales en los que se materialicen de modo tangible las prioridades trazadas por el artículo $1 .^{\circ}$ de la Constitución Política del Perú. Este artículo reconoce que la defensa de la persona humana y la de su dignidad son el fin supremo de la sociedad y el Estado, y que dicho principio debe irradiar eficazmente el ordenamiento jurídico en general y el derecho laboral en particular, sobre todo cuando lo que está en juego es la justificación, la determinación y la eficacia de los derechos fundamentales de las personas más vulnerables.

Por lo brevemente expuesto, puedo concluir señalando que estamos frente a un trabajo que abre perspectivas valiosas tanto para la profundización en la materia por parte de especialistas en derecho constitucional y derecho laboral como para un público mucho más amplio que desde la perspectiva de la familia pueda tener interés en estos aspectos del derecho peruano. 